\title{
O Celeiro Frankliano para A Pós-Modernidade
}

\author{
Pedro Morais Vasques*
}

\begin{abstract}
RESUMO
Este artigo tem como meta explorar e expandir a concepção temporal em sua dimensão do passado na logoterapia a partir da imagem do celeiro utilizada por Viktor Frankl. Cotejamos, ao longo do texto, a concepção frankliana do passado com formulações filosóficas de diversos autores, buscando, assim, melhor entendimento sobre o fenômeno do tempo para a análise existencial. Após o cotejo, abordamos outro problema no âmbito do tempo que aparece ao incluirmos a perspectiva temporal transhumanista no horizonte de pesquisa do campo logoterapêutico.
\end{abstract}

Palavras chaves: Logoterapia, Passado, Transhumanismo

\section{The Franklian BARn for POST-Modernity}

\begin{abstract}
This article has the goal of exploring and expanding on the temporal conception in its past dimension in logotherapy departing from the image of the barn used by Viktor Frankl. We compared, throughout the text, the franklian concept of past with philosophical formulations by multiple authors, hence seeking a better understanding of the time phenomenon in the existential analysis. After the comparison, we approached another issue in the tempo-
\end{abstract}

* Filósofo pela Pontifícia Universidade Católica de Minas Gerais. Especialista em Logoteoria e Análise Existencial pelo Núcleo Mineiro de Logoterapia. Pedro Morais http://orcid.org/0000-0001-9474-9247. 
ral realm which arises as we insert the transhumanist temporal perspective into the field research of the logotherapeutic horizon.

Keywords: Logotherapy, Past, Time, Transhumanism

\section{INTRODUÇÃo}

Como podemos - se é que podemos - nos firmar em segurança em um mundo cada vez mais rápido, danificando com sua aceleração a estrutura temporal cotidiana como a conhecíamos? Há qualquer chance de solidez quando paulatinamente submergimos na liquidez, sufocamos com o esfumaçamento de nosso entorno?

Quando o tempo se descontrola, tudo descontrolar-se-á junto. Uma torção no tempo, mesmo que mínima, torcerá o conjunto das coisas submetidas a ele. Nós quase que nada não sabemos, mas desconfiamos de algumas coisas sugerimos que, se há resgate para o tempo, ele seria encontrado não no nosso futuro, em algo que faremos, mas no passado, algo que fizemos.

0 passado que preserva o que fazemos emerge como oportunidade para equilibrar o tempo, colocá-lo de volta nos eixos. Mas uma outra questão, a partir dessa sugestão, surge: levando em consideração que o passado conserva nossas ações (o que tentarei demonstrar segundo a visão de Viktor Frankl mais à frente), e por conserva-las seria uma chance de concretude atual, o passado talvez não seja tão seguro, devido à quantidade de lixo, literal e metafórico, que produzimos.

0 que um passado, que de celeiro se torna lixão, tem a oferecer?

\section{Um Problema Do Tempo}

Com a transformação da estrutura temporal que a nossa sociedade experimenta, diferentes pessoas - com diferentes estórias - se encontram desnorteadas, sem saber o que fazer, ou mesmo pensar sobre nossa situação. Sofremos com a velocidade do tempo que temos, ou seja, sofremos com o tempo que não temos. Este fenômeno, a volatização do tempo, foi precisamente descrito em 1848, por Karl Marx e Friedrich Engels (2017), no Manifesto do Partido Comunista: "Tudo o que era sólido se desmancha no ar, tudo o que era sagrado é profanado e os homens são finalmente obrigados a encarar sem ilusões a sua posição social e as suas relações com os outros homens" (MARX, ENGELS, 2017, p. 25). Nós nos encontramos nesta situação em que tudo que solidificamos se perde, em que todo esforço nunca é o suficiente. Cremos que a transformação 
da estrutura temporal é, neste quadro, um fator patogênico ${ }^{1}$; faz parte do destino sociológico de nós todos e, como tal, nos determina ${ }^{2}$. Não muitas pessoas celebram esse estilo de vida e são notórios os efeitos danosos do tempo acelerado nas pessoas em geral. Como a logoterapia é chamada a intervir não apenas na patologia individual, mas também na patologia coletiva, acreditamos que é papel permitido a essa abordagem - e dever dos logoterapeutas - se ocupar do tempo e buscarem, na medida do possível, reabilitá-lo para as pessoas ${ }^{3}$.

Mas como isso é possível? Como a logoterapia nos permite contrabalancear o tempo e fazer, assim, com que o tempo seja um fator decisivo para a saúde - e não apenas para a doença? Negligenciar este problema é fechar os olhos para uma das maiores demandas da nossa sociedade. E o problema se estende para além da simples constatação individual e queixosa: sem tempo, a função da memória se perde, e se não temos memória, a compreensão do "eu" perde-se juntamente ${ }^{4}$. É o filósofo sul-coreano Byung-Chul Han (2017) que fala:

Só se pode acelerar um processo que é aditivo, e não um processo que é narrativo. Totalmente transparente é apenas a operação de um processador, porque seu curso é puramente aditivo. Rituais e cerimônias, ao contrário, são processos e acontecimentos narrativos, que se esquivam da aceleração. Seria um sacrilégio querer acelerar uma ação sacrificial, pois rituais e cerimônias têm seu tempo, ritmo e cadência específicos. $^{5}$ (HAN, 2017 p. 70).

1 “Obscena é essa hiperaceleração, que já não é realmente movente tampouco nada leva adiante" (HAN, 2017 p. 70)

2 Sobre o entrelaçamento da instabilidade social e pessoal, Zygmunt Bauman (2009a) disse: “A 'vida liquida' e a 'modernidade líquida' estão intimamente ligadas. A 'vida líquida' é uma forma de vida que tende a ser levada adiante numa sociedade líquido-moderna. 'Líquido-moderna' é uma sociedade em que as condições sob as quais agem seus membros mudam num tempo mais curto do que aquele necessário para a consolidação, em hábitos e rotinas, das formas de agir" (BAUMAN, 2009a, p.7)

3 Frankl (2019) diz: "O que nós precisamos é de respeito ao passado, não ao futuro" (FRANKL, 2019, p. 201)

4 “É sabido que a identidade pessoal está situada na memória e que a anulação dessa faculdade comporta a idiotia" (BORGES, 2010 p. 29)

5 Seguindo a intuição de Byung-Chul Han, poderíamos entender nossa alteração temporal como um ateísmo a priori. Compreendendo sacrifício como sacrum facere, estaríamos, portanto, inabilitados a experimentar fazer algo sagrado já de antemão

Revista Páginas de Filosofia, v. 10, n. 1, p.33-49, jan.-jun. 2021 
Nem tudo pode ser acelerado pois, caso contrário, é destruído; uma narrativa não pode ser acelerada e, levando em consideração que nossa autobiografia é narrativa, acelerar a narrativa é destruí-la (o que pensar do tratamento atual e ordinário da narrativa, quando a possibilidade de acelerar vídeos e filmes, hoje disponível para o público online, busca atender às demandas do público?); um tempo acelerado é aquele que não tem passado, pois é aquele em que nada se foi, tudo precisa ser feito. Um tempo sem passado - levando em consideração a tríade passado-presente-futuro - é um tempo descaracterizado. 0 tempo é um nó borromeano ${ }^{6}$, ou seja, é uma estrutura em que a totalidade depende absolutamente de cada parte; caso uma parte seja removida, a totalidade se desfaz. Como a nossa realidade é essencialmente temporal, descaracterizar o tempo é descaracterizar a realidade. Byung Chul-Han (2017) assina embaixo: "A atual crise epocal não é a aceleração, mas a dispersão e a dissociação temporal. Uma discronia temporal faz com que o tempo gire biruta, sem rumo, transformando-o em mera sequência da atualidade pontual, atomizada" (HAN, 2017, p.77).

Não deveríamos nos surpreender, hoje em dia, com qualquer patologia que surgisse: corromper o tempo é corromper o que há de mais fundamental em nós ${ }^{7}$. Fenômenos como o aumento em $560 \%$ no consumo de remédios para dormir ${ }^{8}$ - apontando, talvez, nossa recusa

6 Em relação ao entrelaçamento total do tempo, diz o físico e filósofo Étienne Klein (2019) "Para que o mundo se mantenha, é afinal preciso que haja um tempo, um tempo que, passando, faça o mundo durar, permita que esse mundo persista como mundo. Mesmo que nesse mundo nada mais se passe, nada mais se mexa, o tempo continua ativo para garantir a continuidade daquilo que é: a cada momento, é ele, o tempo, que toma o 'agora' pela mão para fazê-lo atravessar o presente" (KLEIN, 2019 , p. 25)

7 Sobre o tempo como alma, Santo Agostinho (1996) escreveu sobre, em suas Confissões: Pelo que, pareceu-me que o tempo não é outra coisa senão distensão; mas de que coisa o seja, ignoro-o. Seria para admirar que não fosse a da própria alma (AGOSTINHO, 1996, p. 334). Mais à frente, alega que a vida é distensão: Mas, "porque a vossa misericórdia é superior às vidas" confesso-Vos que a minha vida é distensão. (AGOSTINHO, 1996, p. 338). Tempo é distensão, distensão é alma.

8 Fonte: https://noticias.r7.com/saude/uso-de-remedio-para-dormir-cresce-560-em-oito-anos-03072019 Acesso em 7/8/2020

Revista Páginas de Filosofia, v. 10, n. 1, p.33-49, jan.-jun. 2021 
em confiar no tempo, esquecendo assim a lição de Frankl sobre o sono ${ }^{9}$ - podem ser sinais do sofrimento temporal que passamos. Seria realmente coincidência ouvirmos constantemente a reclamação de cansaço?

Acreditamos que a resposta (ou pelo menos uma tentativa dela) está na visão do passado, de Viktor Frankl, que é resumida na metáfora do celeiro. Frankl reabilita o tempo e a consequência é um entendimento coerente e saudável do tempo, que resgata aquele que o entende da sensação constante de que nada é verdadeiramente concluído e, mesmo se fosse, não valeria em absoluto. Mas antes de tratarmos propriamente do celeiro do passado, precisamos abordar alguns conceitos necessários para compreendermos o que podemos chamar despretensiosamente de "o processo de passar" em Frankl.

Logoterapia é, para Viktor Frankl (2018), psicologia focada no sentido.

Quero explicar por que tomei o termo 'logoterapia' para designar minha teoria. 0 termo 'logos', é uma palavra e significa 'sentido'! A logoterapia [...] concentra-se no sentido da existência humana, bem como na busca da pessoa por sentido (FRANKL, 2018, p. 124).

Em contraposição às outras escolas vienenses, defensoras da vontade de prazer, em Freud, e da vontade de poder, em Adler, Frankl propõe a vontade de sentido como a força motivadora do ser humano. É o sentido que nos movimenta, que nos leva a realizar algo, desde as coisas mais banais até as mais extraordinárias; se algo não fizer sentido, simplesmente não haverá razão ${ }^{10}$ para se ocupar desse algo. Há um jeito ainda mais fácil de entender o sentido do sentido na nossa vida. Em sua mixtape Pra quem já mordeu cachorro por comida, até que cheguei

9 "E então o paciente comete o maior erro possível: ficar à espreita do adormecimento. De maneira tensa e alerta, ele acompanha o que acontece consigo mesmo. Mas quanto mais tensiona sua atenção, menos fica apto a relaxar a fim de conciliar o sono. Pois o sono não é nada além de mergulhar no inconsciente, E tudo que faz pensar nele, e todo desejo de dormir, faz com que a pessoa não consiga dormir" (FRANKL, 2016, p. 214). Para dormir, é necessária a confiança, pois aquele que não confia não se entrega e perde, assim, o único caminho natural ao sono

10 Uma das possíveis traduções para o termo logos é razão, mostrando, na esteira de Frankl, que ver sentido em/para é ver razão em/para.

Revista Páginas de Filosofia, v. 10, n. 1, p.33-49, jan.-jun. 2021 
longe..., o rapper brasileiro Emicida, na faixa intitulada "Só Isso"11, afirma: "Um sábio dizia que você deve comprar arroz e flores. Arroz para viver e flores para ter pelo que viver". 0 sentido são as nossas flores. ${ }^{12}$

Mas o que é a vontade de sentido, nossa energia ${ }^{13}$ ? Em sua obra Teoria e Terapia das Neuroses, Frankl (2016) diz: "chamamos de vontade de sentido simplesmente aquilo que será frustrado no ser humano sempre que ele for acometido pelo sentimento de falta de sentido e de vazio" (FRANKL, 2016, p. 22). Vontade de sentido é definida negativamente neste trecho, sendo o que falha quando sentimos o vazio. Através da consciência, "chamamos a consciência de 'órgão de sentido'”. (FRANKL, 2016, p. 24), somos capazes de captar sentidos. Mas o sentido tem sua especificidade: é único e irrepetível em cada situação para cada pessoa. Viktor Frankl (2018) diz: "Esse sentido é exclusivo e específico, uma vez que precisa e pode ser cumprido somente por aquela determinada pessoa" (FRANKL, 2018, p. 124) e também alega: "De tudo isso resulta o fato de que o sentido, de que aqui se trata, deve mudar de situação para situação e de pessoa para pessoa. Ele é, contudo, onipresente" (FRANKL, 2015, p. 26). O sentido é exclusivo (pois pertence a cada um em cada situação) e inclusivo, pois nos leva compartilhar com o mundo ${ }^{14}$

11 Fonte: https://genius.com/Emicida-so-isso-lyrics. Acesso em 7/8/2020

12 Mais à frente, na mesma faixa, Emicida diz: "Eu tive inclusive pensando ao debruçar na janela, Que enquanto buscam sentido pra vida, eu vivo ela”. Mais uma intuição frankliana do rapper! Em outras palavras: não somos nós que buscamos o sentido, é o sentido que nos busca.

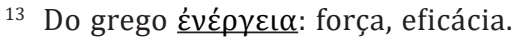

14 Podemos perceber aqui certa proximidade entre o sentido e o amor. 0 sentido nos vem do mundo, ou vida, já que, segundo Frankl, não o podemos criar, e retorna ao mundo, na medida em que nos faz agir, mesmo que apenas de modo passivo, no mundo (como no valor de vivência, por exemplo). Não à toa a frustração existencial mata, pois a intercomunicação com o mundo é rompida e romper comunicação com o mundo é a morte, o suicida apenas concretizando no seu corpo a morte já experimentada. Curiosamente, o amor exerce função parecida. Segundo Frankl, "no amor, como também nas formas mais cotidianas da apreensão da outra existência, o homem sempre se agarrou ao 'concreto' do ser no mundo." (FRANKL, 2019 p. 192). Talvez pudéssemos pensar a logoterapia não apenas como terapia através do sentido, mas também como terapia através do amor.

Revista Páginas de Filosofia, v. 10, n. 1, p.33-49, jan.-jun. 2021 
Somos movidos pela vontade de sentido, sentido esse único e irrepetível - em cada situação e para cada pessoa -, captado pelo órgão de sentido, a consciência. Mas como o passado se forma a partir daqui? Já temos o palco pronto, mas como o drama se desenvolve?

A resposta é simples: pela efetivação. Frankl diz: "Quando tais possibilidades concretizam-se, elas não são mais transitórias" (FRANKL, 2005 , p. 108). Nossa consciência, por se deparar com sentidos exclusivos, está sempre intuindo sentidos. Esses sentidos, por sua vez, precisam sair do estado em que são encontrados, o de possibilidades, e serem transformados em realidades Um exemplo: a vida me mostra o sentido em cuidar de flores ${ }^{15}$; caberá a mim executar tal objetivo valoroso, trazê-lo à luz, ou seja, adquirir as flores, compreender de que tipo são, quais necessidades têm, cuidar delas e, assim, terminar por materialmente temporalizá-lo. É aqui que a dinâmica entre passado-presente-futuro entra, na função parturiente da ação em relação ao sentido. É claro que, se decido cuidar de flores, não posso, ao mesmo tempo em que cuido de flores, praticar algo como alpinismo. Isso quer dizer que, ao escolher por um sentido, condeno ao nada todas as outras possibilidades que são concorrentes, aquelas mesmo que disputaram, com o sentido que escolhi (ou me escolheu), um espaço no mundo material - independentemente de quão certa é essa escolha.

Frankl escreve (2005) "Temos de assumir a responsabilidade por aquilo que tivermos preferido realizar, aquilo que tivermos escolhido para começar a ser parte do passado, que tivermos selecionado para ser eterno!” (FRANKL, 2005, p. 114). Essa é a razão pela qual devemos afinar nossas consciências para deixar-nos atrair pelo sentido adequado ${ }^{16}$, pois a existência mesma de um sentido adequado - a única resposta correta à demanda da vida -, implica a possibilidade de outras respostas, as inadequadas. Frankl (2019) afirma: "Não há dúvida de que para cada possibilidade que salvamos dessa maneira,

15 "O sentido deve ser encontrado, mas não pode ser produzido. 0 que se deixa produzir é um sentido subjetivo, um mero sentimento de sentido, ou de absoluta falta de sentido" (FRANKL, 2015, p. 24).

16 Isso exige do ser humano que ele se recolha e se deixe impressionar. Recolher-se não significa fechar-se na solidão da retração e do desenraizamento, mas entrar em diálogo com o valioso que nos interpela. (QUINTÁS, 2016, p. 119). 
eliminamos milhares de outras possibilidades" (FRANKL, 2019 p. 201). É deste modo que, discernindo através da consciência, movidos pela nossa vontade, guardamos paulatinamente todas as coisas no passado. Viktor Frankl (2018) é claro neste ponto:

Nunca me canso de dizer que os únicos aspectos realmente transitórios da vida são as potencialidades; porém, no momento em que são realizadas, elas se transformam em realidade; são resgatadas e entregues ao passado, no qual ficam a salvo e resguardadas da transitoriedade. Isso porque no passado nada está irremediavelmente perdido, mas está tudo irrevogavelmente guardado. (FRANKL, 2018, p. 144).

O presente, ao passar, não se torna inexistente, mas passa a existir apenas em uma modalidade diferente - modalidade que sustenta o presente. É enganoso, portanto, acreditar que a necessidade de estar sempre fazendo significa que nada se solidifica. Apesar de seu tamanho, vale reproduzir um trecho referente ao passado da obra "A consciência de si", do filósofo Louis Lavelle (2014), devido à sua precisão:

É a indestrutibilidade do passado o que dá à vida seu caráter de seriedade. Se ele não deixasse em nós nenhum traço, viveríamos numa espécie de instantaneidade, sem lembrança nem designío. Se pudéssemos aboli-lo por um ato de vontade, viveríamos numa espécie de instabilidade, fazendo, a cada momento, novas tentativas que logo voltaríamos a mergulhar no nada. No entanto, o passado se conversa por inteiro no presente: é constituído pelas diferentes camadas geológicas que sustentam, juntas, o próprio solo no qual caminhamos. 0 passado tem para nós um caráter profundo, venerável e sagrado ${ }^{17}$. Atravessou

17 Parece-nos que a intocabilidade é o que nos faz sagrados e o que daria à nossa vida o caráter artístico. Segundo Roger Scruton (2013): "As experiências que se concentram no sagrado encontram correspondentes no senso da beleza e no desejo sexual. Talvez nenhuma experiência sexual diferencie de maneira tão clara os homens dos animais do que a experiência dos ciúmes. Os animais competem por parceiros e lutam por eles. Quando, porém, a vitória se consolida, o conflito tem fim. 0 amante ciumento pode ou não brigar, mas a luta não exerce qualquer influência sobre sua experiência, que é uma experiência de profunda humilhação e consternação existencial. Aos seus olhos, o amado foi maculado ou dessacralizado, tornou-se, de certa maneira, obsceno" (SCRUTON, 2013, p. 61). Falaremos mais sobre o caráter artístico da existência mais à frente.

Revista Páginas de Filosofia, v. 10, n. 1, p.33-49, jan.-jun. 2021 
outrora o presente e agora o sustentar sem ser afetado por ele; enraíza nossa vida na eternidade. A antiguidade, a tradição ou simplesmente a velhice suscitaram o sentimento de respeito, que é sempre um respeito diante do ser cumprido: já não é ao vivo que ele se dirige; se ele pereceu, se está prestes a perecer, adquire a majestade das coisas imperecíveis. É por estar inutilizado e não estar sujeito ao uso material que o passado se torna um valor em si, fora de qualquer comparação com nossas necessidades. Todo acontecimento se enobrece na lembrança, que dele só deixa subsistir a ideia, isto é, a significação pura (LAVELLE, 2014, p. $140-141) .{ }^{18}$

O que podemos perceber até aqui? Através do passado, podemos resgatar pessoas de sua percepção distorcida de uma vida em que nada se realiza, em que é preciso estar sempre fazendo, e em que a única coisa que aparece é a ansiedade pelo futuro. 0 passado é seguro, sólido, mantém tudo o que fizemos. Então a logoterapia é mumificante, e sua terapêutica pode ser fotográfica, cinematográfica, aspecto que deve ser, em nossa percepção, largamente explorado ${ }^{19}{ }^{20}$. André Bazin (2018) diz:

18 Quisemos referenciar o filósofo Louis Lavelle apenas devido à sua descrição ser mais pormenorizada e, desse modo, mais exata no que se refere à eternização no passado. Viktor Frankl (2019), nos parece, não discordaria porque, segundo ele mesmo: "Na qualidade de ser histórico, o homem nunca 'é', mas sempre 'vem a ser'. Ele só será um 'todo' quando sua vida tiver terminado; só então seu 'mundo' será completado (FRANKL, 2019, p. 203)

19 Preferimos dizer cinematográfica pois preserva o sentido do movimento e do futuro tão presentes na logoterapia. A foto, por sua vez, refere-se unicamente ao caráter de conservar - uma foto não se movimenta.

20 O central caráter fílmico da logoterapia é destacado por Frankl (2016) no seguinte trecho: "A máxima da análise da existência, poderíamos então revesti-la da seguinte forma imperativa: Vive como se vivesses pela segunda vez e como se da primeira vez tivesses feito tudo tão falsamente como agora estás quase a fazer. [...] Também se pode sugerir aos pacientes que imaginem a sua vida como um filme que estão a 'filmar', mas que não admite 'cortes', isto é, um filme em que já não se pode voltar atrás para desfazer o que foi 'tomado. Desta maneira também se consegue, uma vez ou outra, fazer ver o caráter irreversível da vida humana, a historicidade da existência" (FRANKL, 2016, p. 146. Há, aqui, uma curiosa ligação entre: filme, sentido da vida, irreversibilidade e morte; sendo o primeiro elemento, o filme, uma porta privilegiada para a máxima da análise da existência e, portanto, para a responsabilidade. Trataremos à frente da irreversibilidade

Revista Páginas de Filosofia, v. 10, n. 1, p.33-49, jan.-jun. 2021 
Uma psicanálise das artes plásticas poderia considerar a prática do embalsamamento como um fato fundamental de sua gênese. Na origem da pintura e da escultura, descobriria o 'complexo' de múmia. A religião egípcia, toda ela orientada contra a morte, condiciona a sobrevivência à perenidade material do corpo. Com isso, satisfazia uma necessidade fundamental da psicologia humana: a defesa contra o tempo. (BAZIN, 2018, p. 27-28)

A logoterapia recebe, por isso, um caráter de conservação - sem perder o dinamismo - e se torna cinematográfica. Podemos, então, remediar a perda de fundamentos, a característica da pós-modernidade, por meio do passado - o fundamento de tudo. Santo Agostinho (2014), em "Sobre a vida feliz", diz: "Portanto, de modo algum duvidamos que alguém decidido a ser feliz deve tentar alcançar algo que seja perene, que não possa ser-lhe roubado por algum acaso incontrolado." (AGOSTINHO, 2014 , p. 19) Agostinho pretende apontar Deus como o fundamento da felicidade, pois é eterno e, nessa condição, podemos depositar nele nossa confiança. Tal possibilidade, na pós-modernidade, nos é barrada em sua pureza. É possível, apesar da falta de fundamentos, apelarmos ao passado como o solo seguro de todas as experiências, pois o que é passado no passado permanece, segundo Frankl, sem poder jamais ser perdido. Apenas uma diferença deve ser demarcada: para Agostinho, a fonte de nossa felicidade é perene e infinita, pois é Deus; para Viktor Frankl é também perene, mas finita, pois é uma perenidade construída. 0 que é confirmado pela seguinte declaração frankliana: "a eternidade é finita: só colhemos o que desejamos admitir na eternidade" (FRANKL, 2005, p. 115). Em outras palavras: em Agostinho, a eternidade é e o homem a adora, a contempla; em Frankl, deve ser, e por isso o homem a faz.

Uma objeção, que devemos admitir ser plausível - e por isso mesmo devemos antecipá-la -, pode ser levantada ao argumento anterior: a logoterapia e os logoterapeutas confundem o passado com a memória, de modo que o passado realmente desaparece, mas o que sustenta a ilusão de sua permanência é a memória que temos dele. Caso mais ninguém se lembre de um evento passado ele, efetivamente, extinguiu-se.

Apesar de sua razoabilidade, não é essa a concepção que Viktor Frankl propugna. Frankl afirma explicitamente que "Identificar como 
parte do passado apenas aquilo que ainda é lembrado seria uma interpretação falha e subjetivista de nossa ontologia do tempo. Essa ontologia, longe de ser uma espécie de torre de marfim com elevado nível de abstração, pode ser clara até para o homem comum" (FRANKL, 2005, p. 110). Sendo de simples compreensão, poderemos empreender mais essa correção sem nos estendermos em demasia.

Ao passado, para Viktor Frankl, corresponde a metáfora do aluvião ${ }^{21}$. 0 que a noção de aluvião nos aponta é que o tempo passa constantemente mas não desfaz-se; ao contrário, solidifica-se, torna-se o solo a partir do qual vivemos nossa vida. Se o passado efetivamente se extinguisse, não apenas não haveria presente, mas também toda a história, e cada estória em particular, deveria necessariamente recomeçar infinitas vezes - e não é isso o que verificamos. Em uma vida saudável, o passado está guardado e, por isso mesmo, "esquecido" como o chão que pisamos. Do mesmo modo que ao caminhar não prestamos atenção no chão, mas sim em nosso destino, nossa atenção não sustenta o passado, mas o futuro. Esta breve exposição é sumarizada por Frankl no seguinte trecho: "Fica evidente agora que a logoterapia apresenta não só um "otimismo do passado" (em contraste com o "pessimismo do presente' do existencialismo), mas também um 'ativismo do futuro'” (FRANKL, 2005, p. 114).

Resgatamos o passado, conforme Frankl, trazendo um modo de concebê-lo mais saudável, menos desesperador. Tudo o que fazemos está guardado, defendido pela imutabilidade do passado ou, como Frankl mesmo escreveu: $O$ tempo flui, mas o acontecimento se coagula em forma de história. Nada que aconteceu pode ser desfeito. Nada que foi criado pode ser exterminado. No passado nada está irreparavelmente perdido. No ser-passado está tudo absolutamente preservado. (FRANKL, 2019, p. 200). 0 escritor argentino Jorge Luís Borges (2013) escreveu em sua poesia Everness (BORGES, 2013, p. 53):

Everness

21 O tempo flui, mas o acontecimento se coagula em forma de história. Nada que aconteceu pode ser desfeito. Nada que foi criado pode ser exterminado. No passado nada está irreparavelmente perdido. No ser-passado está tudo absolutamente preservado. Reformulando tudo isto no jargão da geologia; vivemos num eterno aluvião (FRANKL, 1978, p. 150)

Revista Páginas de Filosofia, v. 10, n. 1, p.33-49, jan.-jun. 2021 
Só uma coisa não há. O esquecimento. Deus, que salva o metal, salva a escória E anota em sua profética memória As luas que serão e as que já foram

Tudo já está. Os milhares de reflexos Que em meio aos dois crepúsculos do dia Teu rosto foi deixando nos espelhos E todos os que ainda deixará.

E tudo é uma parte do diverso cristal desta memória, o universo; nunca têm fim seus árduos corredores

e as portas vão fechando quando passa; somente do outro lado do poente verás os Paradigmas e Esplendores

\section{Um Outro Problema De Tempo}

Após a investigação anterior, o problema se altera e é justamente após a alteração que a questão do passado se torna ainda mais interessante. Se o tempo passa rapidamente, obrigando-nos a fazer em excesso e se, após retificarmos o conceito de passado, compreendendo que tudo passa não para o nada, mas para a eternidade - como aponta Louis Lavelle -, então o problema é invertido: nosso tempo não é o tempo sem tempo, não é o tempo em que precisamos fazer tudo porque nada dura; é o tempo em que temos tempos demais, tempos em excesso, e é isso que nos adoece.

Como poderíamos fazer tantas coisas, empreender tantos projetos, se nos faltasse tempo?

0 problema que, acreditamos, os logoterapeutas terão que encarar daqui para frente não é mais o da transitoriedade de todas as coisas, mas sim o de um acúmulo cada vez mais acentuado - uma perenidade insuportável. Nosso celeiro do passado está deixando de ser um celeiro cuidado, trabalhado, discernido de acordo com sua singularidade, e está se tornando um lixão, um lugar onde descartamos todas as coisas que somos impelidos a fazer, e que, por isso, fazemos com indiferença. É o filósofo italiano Giorgio Agamben (2014) que nos dá uma pista para pensar essa situação: 
O homem é vivente que, existindo sob o modo da potência, pode tanto uma coisa como seu contrário, pode tanto fazer como não fazer. [...] É sobre essa outra e mais obscura face da potência que hoje prefere agir o poder que se define ironicamente como 'democrático'. Este separa os homens não apenas e não tanto daquilo que podem fazer, mas, em primeiro lugar, e principalmente, daquilo que podem não fazer. Separado da sua impotência, privado da experiência do que pode não fazer, o homem moderno crê-se capaz de tudo e repete seu jovial 'não há problema' e o seu irresponsável 'pode-se fazer (AGAMBEN, 2014, p. 72).

Este é o novo tópico para os que se ocupam com a logoterapia: o nosso passado está se tornando, a cada dia mais, pura tralha. Nossa capacidade de não fazer nos tem sido subtraída, tomada, o que nos leva a experiências irrelevantes e, desse modo, a um passado irrelevante, sem sentido. Zygmunt Bauman (2009b) já destacou como um dos danosos sintomas de nosso tempo a quantidade de lixo. Ele afirma:

Há uma perspectiva plausível de a modernidade capitalista (ou do capitalismo moderno) se afogar em seu próprio lixo que não consegue reassimilar ou eliminar e do qual é incapaz de se desintoxicar (há numerosos sinais de cada vez mais alta toxicidade do lixo que se acumula rapidamente) (BAUMAN, 2009b, p. 35).

O mais assustador do diagnóstico é que Bauman não está tratando unicamente do consumismo, mas sim de pessoas; pessoas essas que, por não terem para onde ir, são "lixo humano". Não poderíamos abordar o consumismo como fruto da lixificação da existência? Uma breve digressão pode aclarar uma resposta a essa pergunta: quem descartaria um objeto imantado pela atenção, carinho ou preocupação de um amigo? Quem indiferentemente jogaria fora algo revestido de amor?

Perdemos o nosso "não" a tal ponto que já flertamos com a ficção. O que parece distante, está cada dia mais próximo e se aproxima silenciosamente. Pensemos, como ilustração, no transhumanismo. O que é isso? Em entrevista dada a Jorges Forbes, transcrita como prefácio à edição brasileira do livro A Revolução Transhumanista, Luc Ferry (2018) diz:

Em outras palavras, o transhumanismo é deixar a humanidade melhor. É melhorá-la. Em inglês se diz enhacement. Trata-se de passar de um 
modelo terapêutico que tratava (o médico estava ali para tratar, consertar) para o modelo do aumento. E o verdadeiro projeto por trás de tudo isso é aumentar não só a inteligência, a beleza, a força, mas a longevidade humana. A Google investe bilhões de dólares no projeto de aumento da longevidade humana. A ideia é fabricar uma humanidade que seria jovem e velha ao mesmo tempo. 'Se a juventude soubesse, e a velhice pudesse', diz um famoso provérbio. Trata-se de fabricar uma humanidade que viveria 150, 200, 300 anos, talvez até mais. Isso já foi feito com ratos: os ratinhos transgênicos da Universidade de Rochester vivem trinta por cento mais tempo que os ratos normais. $A$ ideia é fabricar uma humanidade que viveria muito mais tempo e, claro, em boa saúde (FERRY, 2018, p. 9)

0 projeto transhumano é: fabricar uma humanidade melhorada, que viva cada vez mais e, talvez, para sempre ${ }^{22}$.Com o avanço científico, temos como projeto erradicar as doenças e prolongar a vida; o transhumanismo apenas pretende levar esse raciocínio às suas consequências últimas: a extinção da mortalidade ${ }^{23}$. 0 fato incômodo é: mesmo que digamos para nós mesmos que a realização de tal lógica imortalista ocorrerá apenas em um futuro distante, sua lógica já vige; afinal de contas, nenhum de nós acha de bom augúrio morrer jovem e, feliz e inquestionavelmente, aumentamos nosso tempo de vida. Caso tais empresas continuem a alcançar seus objetivos, a logoterapia se deparará com o seguinte problema: com uma vida cada vez mais longa temos cada vez mais lixo, ou seja, um passado cada vez mais irrelevante.

Os propósitos prometeicos do transhumanismo aparecem de forma didática nas declarações e projetos do biogerontologista inglês Aubrey De Grey. Sobre Grey, afirma Hugh Aldersey-Williams:

${ }^{22}$ Afirmou Jean Paul Sartre: "Pode-se dizer, assim, que o que torna mais compreensível o projeto fundamental da realidade humana é afirmar que o homem é o ser que projeta ser Deus". (SARTRE, 1997, p. 693)

23 Enquanto os imortalistas buscam meramente modos para viver mais tempo ou para sempre em nosso próprio corpo, os trans-humanistas desdenham por completo da existência corpórea e desejam escapar dela. Seu objetivo consiste em ser capaz de dar um 'upload' na nossa mente, conectando-a a alguma imensa rede etérea, deixando totalmente de ser dependente da carne ou, por sinal, da biosfera necessária para sustentá-la. (ALDERSEY-WILLIAMS, 2016, p. 332). 
Seus primeiros trabalhos teóricos, publicados em periódicos especializados em gerontologia, dedicavam-se ao estudo da teoria do envelhecimento por radicais livres, que sustenta que o envelhecimento pode ser atribuído a um dano progressivo às células do corpo infligido por oxidantes outros radicais livres (moléculas com elétrons desemparelhados) [...] As especulações de Grey tornaram-se mais polêmicas e de maior alcance. [...] Ele se atreveu a tratar não só da interrupção do envelhecimento, mas de fato de sua reversão, e de fazer isso 'em questão de décadas' (ALDERSEY-WILLIAMS, 2016, p. 324).

Não foi o próprio Viktor Frankl (2016) que destacou que a morte é fulcral para o sentido da vida? "A finitude, a temporalidade, não é apenas, por conseguinte, uma nota essencial da vida humana: é também constitutiva de seu sentido. 0 sentido da existência humana funda-se no seu caráter irreversível (FRANKL, 2016, p. 145)" Frankl já aventou a possibilidade da imortalidade encarnada e disse: Se fôssemos imortais, poderíamos, com razão, adiar cada uma das nossas ações até o infinito; nunca teria a menor importância realizá-las agora, neste momentos preciso, podendo muito bem realizar-se amanhã ou depois de amanhã, ou daqui a um ano ou dez. Em compensação, tendo em vista a morte como fronteira infranqueável do nosso futuro e limite de nossas possibilidades, vemo-nos obrigados a aproveitar o tempo de vida de que dispomos e a não deixar passar em vão as ocasiões irrepetíveis que se nos oferecem, ocasiões essas cuja soma 'finita' representa precisamente a vida toda" (FRANKL, 2016, p. 145). Como poderíamos perceber o chamado do sentido de cada situação se ele deixaria, nesse caso, de urgir? Como haveria, nesse caso, liberdade da vontade, vontade de sentido e sentido da vida? Estaríamos nos aproximando paulatinamente do tédio, do tédio eterno? Se é o sentido que nos faz viver, também não poderíamos por ele morrer e ao escolher a morte, uma vida seja valorosa graças à finitude? ${ }^{24}$ Algum dia teremos que dizer sim à morte, apesar de tudo? ${ }^{25} 26$

24 “(o que se denomina razão de viver é ao mesmo tempo uma excelente razão de morrer)" afirmou certa vez Albert Camus (CAMUS, 2013, p. 18)

25 "Devemos lidar, na verdade, com uma posição otimista, ou seja, com a convicção de que até a morte e o sofrimento têm, potencialmente, sentido" afirma Frankl (FRANKL, 2020, p. 103)

26 Encontraríamos aqui, novamente, uma fronteira mal traçada entre realidade e ficção. Uma vida cuja duração é indeterminada e, graças a isso, tediosa, é característica de certas representações vampirescas. "é por isso que nos contos clássicos de vampiros

Revista Páginas de Filosofia, v. 10, n. 1, p.33-49, jan.-jun. 2021 


\section{Considerações Finais}

Acreditamos ter levantado, a partir de contribuições de Viktor Frankl, contrapontos consideráveis a determinada noção de tempo já popularmente disseminada na contemporaneidade entre as pessoas disseminação essa perceptível em suas falas cotidianas. Propusemo-nos a rebater a noção corrente de tempo, aquela que inadvertidamente compreende o tempo como um átomo evanescente, servindo-nos do que Frankl destaca em relação ao passado: sua imperecibilidade. Entretanto, a imperecibilidade do passado, que fora apresentada anteriormente como solução, é ela mesma vista, num momento posterior como um segundo problema quando justaposta às proposições do movimento transhumanista e sua implicação temporal mesma, na medida em que, a partir de uma perspectiva incrivelmente duradoura de existência humana, a questão do passado se rearranja e apresenta-se não mais como o celeiro, mas como uma coleção desconexa e desarmônica de nossas decisões. Arriscamos, através deste artigo, uma resposta ao problema do tempo cotidiano e, como já afirmamos, cremos ter elencado argumentos razoáveis para soluciona-lo. Não arriscamos, porém, resposta alguma no que se refere ao segundo problema. A resposta, se é que há alguma, deverá ser construída pela logoterapia e pelos logoterapeutas.

\section{REFERÊNCIAS}

AGOSTINHO, Santo. Confissões. São Paulo: Nova Cultura Ltda, 1996 AGOSTINHO, Santo. Sobre a vida feliz. Rio de Janeiro: Vozes, 2014 ALDERSEY-WILLIAMS, Hugh. Anatomias. Rio de Janeiro: Record, 2016 BAUMAN, Zygmunt. Vida líquida. 2. ed. Rio de Janeiro: Zahar, 2009a BAUMAN, Zygmunt. Tempos líquidos. Rio de Janeiro: Zahar, 2009b BAZIN, André. o que é o cinema? São Paulo: Ubu, 2018 BORGES, Jorge Luis. História da eternidade. São Paulo: Companhia das Letras, 2010

(a começar pelo Drácula, de Bram Stoker), vemos os 'mortos-vivos' acolherem com serenidade (e, o que é ainda mais, com uma alegria passiva mas real) o momento final de aceitação em que [...] seu corpo físico se converterá enfim [...] em pó" (HUTIN, 2010, p. 105) 
BORGES, Jorge Luis. Nova antologia pessoal. São Paulo: Companhia das Letras, 2013 CAMUS, Albert. 0 mito de Sísifo. 10. ed. Rio de Janeiro: Record, 2013

FERRY, Luc. A revolução transhumanista. Barueri: Manole, 2018

FRANKL, Viktor. Fundamentos antropológicos da psicoterapia. Rio de Janeiro: Zahar, 1978

FRANKL, Viktor. Um sentido para a vida: psicoterapia e humanismo. Aparecida: Ideias \& Letras, 2005

FRANKL, Viktor. 0 sofrimento de uma vida sem sentindo: caminhos para encontrar a razão de viver. São Paulo: É Realizações, 2015

FRANKL, Viktor. Psicoterapia e sentido da vida: fundamentos da logoterapia e análise existencial. São Paulo: Quadrante, 2016

FRANKL, Viktor. Teoria e terapia das neuroses: introdução à logoterapia e à análise existencial. São Paulo: É Realizações, 2016

FRANKL, Viktor. Em busca de sentido: Um psicólogo no campo de concentração. 44. ed. Petrópolis: Vozes, 2018

FRANKL, Viktor 0 Sofrimento Humano: fundamentos antropológicos da psicoterapia. São Paulo: É Realizações, 2019

FRANKL, Viktor. Psicoterapia e existencialismo: Textos selecionados de logoterapia. São Paulo: É Realizações, 2020

CHUL-HAN, Byung. Sociedade da transparência. Petrópolis: Vozes, 2017

HUTIN. Sergei. História Geral da Alquimia: a tradição secreta do Ocidente, a pedra filosofal e o elixir da vida. São Paulo: Pensamento, 2010

KLEIN, Étienne. 0 tempo que passa (?). São Paulo: 34, 2019

LAVELLE, Louis. A consciência de si. São Paulo: É Realizações, 2014

MARX, Karl; ENGELS, Friedrich; ILICH LÊNIN, Vladimir. Manifesto Comunista; Teses de Abril: Com textos introdutórios de Tariq Ali. São Paulo: Boitempo, 2017

QUINTÁS, Alfonso López. 0 conhecimento dos valores: introdução metodológica. São Paulo: É Realizações, 2016

PAUL, Jean-Paul. o ser e o nada: Ensaio de ontologia fenomenológica. Petrópolis: Vozes, 1997

SCRUTON, Roger. Beleza. São Paulo: É Realizações, 2013

Revista Páginas de Filosofia, v. 10, n. 1, p.33-49, jan.-jun. 2021 